\title{
Conceptual and Linguistic Transfer from L2 (Catalan) to L1 (Amazigh) within the Context of Migration
}

\begin{abstract}
This paper focuses on the analysis of the lexical and semantic influences of L2 (Catalan) on the L1 (Amazigh) in a basic semantic field: parts of the body. Based on the observation that our participants show differences in their L1 usage related to the amount of time they have been in contact with Catalan, our goal is to analyze and describe these differences to see if they are the consequence of a transfer from the L2 conceptual system. This paper is a qualitative study with a sample size of 14 participants whose L1 is Amazigh and who live in Catalonia. The results show that there are cases of semantic and conceptual influence, although to a lesser degree than in other studies that do not analyze data from basic semantic fields. We will also show that there are extralinguistic factors that influence these transfers (the status of the languages involved and certain characteristics of the speakers).
\end{abstract}

Keywords: Semantic categorization, crosslinguistic transfer, conceptual transfer, Catalan, Amazigh, bilingualism, multilingualism

The relationship between language and thought has been studied from various perspectives in research on bilingualism, beginning with linguistic relativity, which was developed by Whorf (1956) and has been adapted over the years (Slobin, 1996; Lucy, 2016). Linguistic relativity studies the effects of language on thought. However, other research focuses on the influence of thought on language. Crosslinguistic influence is another point of view from which this relationship has been studied, especially as regards conceptual transfer (Jarvis \& Pavlenko, 2008). These studies research how the ideas of conceptualization that have been acquired through a language affect the use of another language and how the transfer can be bidirectional, between the two languages involved (Cadierno \& Ruiz, 2006; Jarvis, 2016). Other recent studies 
(Aveledo \& Athanasopoulos, 2016; Park, 2019) use a theoretical framework that combines both abovementioned perspectives.

This paper falls under the research field of crosslinguistic influence and focuses on lexical conceptual transfer issues. It will analyze the influence that L2 has on L1 for Catalan speakers of Amazigh origin regarding the categorization and conceptualization of a basic semantic area: parts of the body. This research on crosslinguistic influence is based on results obtained through a sample of bilingual or multilingual speakers who speak at least Amazigh and Catalan. ${ }^{1}$ When referring to bilingualism or bilingual speakers, one must distinguish between speakers who have grown up learning both languages simultaneously and those who have learned their L2 later (Cook, 2003). We will refer to the latter case for this study: all participants have learned Catalan after Amazigh and, furthermore, they all speak at least one other language. This will be described in detail later.

The data analyzed have been obtained from speakers who live in a migratory context in which many languages are involved. These data differ from those in many studies that have been produced regarding bilingualism, crosslinguistic influence, and conceptual transfer. Such research usually focuses on speakers who know two languages, with the L2 usually being English. The status of the two languages addressed in this work, both minoritized languages yet with different sociolinguistic situations, is therefore quite different from the status of languages that are often studied in research on bilingualism.

The lexical and semantic data will be approached from the point of view of cognitive semantics, which is the theoretical framework that encompasses the conceptual transfer hypothesis. This hypothesis assumes that each language shows how speakers categorize and conceptualize reality, and that the differences that languages reflect will be transferred, potentially, from one language to another with bilingual or multilingual speakers (Bylund \& Jarvis, 2011).

This study builds upon other studies comparing how body parts are categorized in Catalan and Amazigh (Ferrerós, 2015; Múrcia \& Zenia, 2015). These studies are essential in knowing if there has been a conceptual transfer in the results obtained in producing L2, as to determine whether such transfer has occurred or not it is necessary to previously and separately study each of the languages involved. This previous study is important when taking into account that categories are not always labelled in the languages. It is possible for two

\footnotetext{
1 The Amazigh language, of the Afro-Asiatic family, is the proper language of North Africa, most commonly spoken in Morocco and Algeria but also in Libya, Nigeria, Burkina Faso, Niger, Mali, Mauritania, Tunisia, and Egypt. It is the L1 of almost half the population of Morocco. This study focuses on the Riffian (North Morocco) Amazigh variety. The biggest migrant community in Catalonia is of Amazigh origin. Hence the relevance of interlinguistic studies such as this one, as these languages come into contact with each other oftentimes in the migration context (Barrieras, 2013).
} 
languages to similarly categorize a reality segment, but one not labelling said category. Therefore, a crosslinguistic difference does not necessarily show a difference in categorization. That is to say, the fact that one language does not label a reference that another language does label does not imply that speakers of the former do not categorize a given part of the body. If the categorizations were the same, one could not speak of conceptual transfer even if we observed a crosslinguistic influence. This is why it is essential to have previously analyzed the two languages in order to produce research as found herein.

\section{Literature Review}

\section{Semantic Categorization}

One of the cognitive activities that human beings do is related to classifying and organizing reality in order to give it meaning. We create categories that usually take the form of words or morphemes in language. Each language shows different categorizations of reality, although there are certain limits regarding diversity. From the point of view of cognitive studies, the ability to categorize is a vital cognitive ability for the survival of living beings, which consists of grouping the world's objects and events according to the similarities they present.

Cognitive semantics draw from the prototype theory formulated in the seventies by Rosch $(1973,1878)$. The categories that are created are gradual, and there are elements that occupy central positions and share more information among themselves than with other elements that occupy less central positions. The more central an element is in a category, the more features it shares with the prototype, which is the most characteristic element (Rosch, 1978). The effects of the prototype are not only produced in individual meanings, but also between the different meanings of the same polysemous word. Polysemy is the phenomenon by which the various meanings of a word are related to each other, if there is an embodied reason, that is, if the categorization is related to how humans experience the world. The phenomena that operate at the foundation of semantic extensions are metaphorical or metonymic (Lakoff, 1987; Ibarretxe-Antuñano, 1999).

The terms for parts of the body refer to a reality that is the same for everyone, enabling us to study how humans experience this reality as an integral part of ourselves and how this influences our cognition. Crosslinguistic differences also help us see if there are cultural factors that condition categorization. The categorization of the human body has been studied from various, 
non-exclusive points of view: lexical typology (for example, Andersen, 1978; Brown, 1976; Enfield, Majid, \& Van Staden, 2006; Wierzbicka, 2007) and cognitive semantics, especially in matters related to the notion of polysemy (Ibarretxe-Antuñano, 1999, 2010).

\section{The Transfer of L2 to L1 with Bilingual or Multilingual Speakers}

One of the most frequently discussed issues in bilingualism and second language acquisition is the mutual interference of the languages involved in these processes. Jarvis (2011, p. 1) claims that crosslinguistic influences occur not only in grammatical phenomena but also in the choice of words and discursive structures. These differences often reflect ways to convey specific meanings in a given language.

Jarvis (2016, p. 609) explains that crosslinguistic influences can be related to (1) the constraints of good linguistic formation; (2) the relationship between form and meaning; and (3) the specific ways how meanings are represented in the minds of the speakers. He calls influences of the first kind linguistic, those of the second semantic, and those of the third conceptual. This use of terminology seems inadequate as we view conceptual aspects as also being linguistic and semantic. If we take into account contributions framed within lexical typology and cognitive semantics that have focused on the study of the lexicon and the conceptualization of meanings (see, for example, Koch, 2005), we see that the conceptual aspects correspond to paradigmatic distinctions (considering lexical and morphological pieces as elements of an inventory), while other issues depend on syntagmatic organization (if the lexical and morphological elements are considered part of a sequence). The paradigmatic lexical distinctions can be studied from a semasiological or onomasiological point of view (Koch, 2005, p. 12). The latter aims to explain how conceptual material is organized in relation to lexemes and how the concepts expressed are organized, and it is one of the points of view used in this papeBylund and Athanasopoulos (2014) and Pavlenko (2014) claim that learning a language and the changing circumstances of people's language experience can be accompanied by cognitive changes. Jarvis (2016) explains that investigating the relationship between multilingual people's language and cognition also facilitates understanding which phenomena are related to crosslinguistic influence and that reflect cognitive and conceptual tendencies conditioned by the languages spoken. Adding to Jarvis's assertions, the differences in conceptualization can also be the result of other nonlinguistic factors, which can be related to culture, the individual's education, the methodology used to obtain the speakers' speech, and more. Although this paper focuses on linguistic issues related to the semantic categorization shown 
in the lexicon, we will also consider these other phenomena in the analysis of the results.

Studies on conceptual transfer are based on the hypothesis that some cases of crosslinguistic influence on language use are due to the concepts and mental patterns of conceptualization that a person has acquired as a speaker of another language (Bylund \& Jarvis, 2011). According to Jarvis (2016), issues related to conceptual transfer can be researched from points of view closer to linguistic relativity (using non-verbal data to research conceptualization) or traditional research on crosslinguistic influences (making use of verbal data to observe what linguistic influences occur between the languages involved). There are also intermediate points of view that take into account linguistic data to study crosslinguistic influences related to conceptualization.

In this study, we will primarily use linguistic data, as we will explain in section Methodology. Issues related to conceptual transfer will be analyzed through the description, analysis, and interpretation of the language used by the bilingual speakers interviewed for this study. The analysis of the results will be conducted based on the framework proposed by Pavlenko (2000) regarding the study of transfers, which can be applied to the analysis of any type of transfer or influence processes between two languages: the adoption of borrowing from one language to another, crosslinguistic convergence, the displacement of structures or values from one language to a speaker's own language, language restructuring, and the erosion of one of the two languages. Furthermore, we will make a distinction, which we find particularly relevant for the study of conceptual transfer, between cases of crosslinguistic lexical influence that involve recategorization and those that simply introduce or redistribute labels for concepts that are categorized but not necessarily labelled (Wierzbicka, 2007).

\section{Methodology}

\section{Sample Size}

This is a qualitative study: the sample size is composed of 14 participants and the selection of participants did not end until there was no further new data, that is, until saturation was reached. The general criterion for inclusion of the participants in the sample was that their L1 was Riffian Amazigh and their L2 was Catalan. In addition, their contact time with Catalan was taken into account, leading us to create three groups: (1) participants who have spent more time in Catalonia than in Morocco (5 participants); (2) participants who 
have spent approximately the same time in Catalonia and Morocco (4 participants); (3) participants who have lived in Catalonia for less than five years at the time of the interview (5 participants). Within each group, participants with different ages and educational levels were included as we deemed that these variables could influence responses.

Although studies on the influences between L1 and L2 that we have referred to almost all use a sample of adult participants who are bilingual, participants in our study were multilingual: Berber, Catalan, Spanish, Moroccan Arabic, Standard Arabic, French, and so on. In addition, our participants showed remarkable differences between one another: the linguistic profiles of Amazigh speakers who were educated in Catalonia, that is, the participants in the first group, are quite different from Amazigh speakers who were not (they speak neither Moroccan Arabic nor Standard Arabic). The latter group also shows differences depending on whether they were educated or not. We will make references to these variables as appropriate.

The fact that the speakers in the sample are multilingual is related to the idea of mixed linguistic identities. Rampton (2017, p. 338) points out that "the idea that people really only have one native language, that really monolingualism is the fundamental linguistic condition, also underlies a widespread failure to recognize new and mixed linguistic identities." Related to this, authors such as Cook (1999) and Grosjean (1998) have proposed the theory of multi-competence by which a multilingual person has a compound mental state that is not equivalent to two monolingual states.

Besides the group of participants indicated, three participants living in Morocco with knowledge of linguistics who know neither Catalan nor Spanish contributed to deepening and expanding the information taken from Riffian Amazigh lexicographical sources.

\section{Procedures}

The data in the study comes, first, from a thorough review of the following dictionaries: Serhoual (2002), Sarrionandía and Ibáñez Robledo, (2007 [1944, 1949]), Naït-Zerrad (1997; 1999; 2002), and Múrcia and Zenia (2015). The first two cover Riffian Amazigh. The other two are pan-Amazigh.

As we have noted in the introduction (The Transfer of L2 to L1 with Bilingual or Multilingual Speakers), Jarvis (2016) mentions the use of verbal data in understanding the conceptualization that a given language shows. Jarvis affirms that this question is usually answered through the analysis of verbal responses in perception, categorization, and memory tasks such as those used in the field of psychology. In addition, he also adds data from narrative tasks or tasks with more open references. That is why we have used a combined 
methodology for this research, with psycholinguistic tasks followed by a more open task.

The first task was to make a list of words for body parts in their L1, with the objective of understanding which ones were most commonly used by participants, and thus, which are perceptively more relevant. Next, participants did the body coloring task (Van Staden \& Majid, 2006), the objective of which was to understand the extent of the references of the words for body parts with imprecise boundaries. ${ }^{2}$ The third task was based on extralinguistic stimuli consisting of images that the speakers had to name and describe. Finally, they participated in a semi-structured interview (about 90 minutes in length) in which they were asked about words and meanings (literal and non-literal) for body parts.

An in-depth reading was the first step in order to analyze the responses obtained in the interview. Then, the most relevant units of meaning were taken, which were grouped into categories based on common characteristics. Finally, the contents were interpreted. The results set out in the next section are organized into sub-sections taking into account the established categories.

\section{Results}

In order to obtain and analyze the results, we began with categorization and labelling differences seen in Catalan and Amazigh (Ferrerós, 2015; Múrcia $\&$ Zenia, 2015). These differences, which can result in cases of transfer and influence from L2 to L1, allowed us to create the categories under which we have divided this section. Regarding the study on the use of non-literal meanings, we will describe the words that present vagueness or polysemy and whose uses are related to anatomical references. Next, we will describe the cases that present differences with respect to the use of non-literal meanings for a polysemic word in both languages (cor, ul, 'heart'). Finally, we will describe data related to differences in knowledge and the use of words for body parts.

Each section will be headed by a list of the words employed on each part. These words are primarily obtained from lexicographical sources. It is important to note that the selection and classification is sourced from

2 The words analyzed in this task were the following: acddis 'belly,' tayrudt 'shoulders,' afus 'hand/arm,' idmarn 'chest,' iyzdisa 'side,' iri 'neck,' ayil 'arm/shoulder,' adar 'leg/foot,' tacddist tamzziant 'lower abdomen,' acrur 'back,' tahbut ijiman 'nape hollow,' amggiz 'cheek,' anzarn 'nose,' aynbub 'face,' udm 'face,' tawarna 'forehead,' tamart 'beard/chin,' takmmart 'lower side of the face.' 
the semantic information obtained through the interviews: the hereby analyzed cases are the ones showing differences from Catalan (so they might generate transfers). These differences will be subsequently described in the following sections.

\section{Differences in Categorization and Labelling}

Terms in Amazigh without an equivalent in Catalan. Amazigh has names for certain body parts which are not named in Catalan. The words presented here refer to perceptively not very relevant body parts: they never appear in the list task, which is the first participants are asked to complete.

Table 1

Terms in Amazigh without an equivalent in Catalan

\begin{tabular}{ll}
\hline addiy $\mathrm{n}$ taddaxt & 'jugular notch' \\
akmmar & 'lower part of the face' \\
arbub $\mathrm{n}$ tiymas & 'tooth growing close to another tooth' \\
\hline
\end{tabular}

In Amazigh, the jugular notch is labelled with the nominal expression addiy $n$ taddaxt (literally, 'shoulder hole'). Use of this term is highly specialized: it is employed when talking about a woman's beauty. Most of the younger speakers, under 25 years of age, do not recognize the term. Only one of the younger speakers recognized the term, stating that his mother uses it but not him.

The word akmmar is only used by the two oldest speakers who are the participants that have spent a longer period in Morocco than in Catalonia. Both the body coloring task and the semistructured interview show that this word refers to the lower part of the face (from the nose to the chin) and the speakers explain that it is usually used to refer to the appearance of this part of the face when a certain facial expression is made. The oldest participant said that akmmar "means, for example, that somebody was unhappy, someone came and they made a bad takmmart."

The final term, arbub $n$ tiymas, refers to a tooth growing too closely to another one, causing dental health problems. The first component, arbub, is related to the verb arbu 'to carry a load' (Serhoual, 2002: $r b$ ). Only four participants use this expression, although they do not associate arbub with the verb arbu. Three of these four speakers were over 40 years of age when the interview was conducted, and the two oldest ones had lived in Morocco

3 This participant inflects the word in feminine $(t \ldots t)$. In Amazigh, gender inflection can convey certain semantic contents. In this case, it conveys the idea of the diminutive. 
longer than in Catalonia. None had completed education beyond grade school. The fourth participant who already knew and used the expression was 35 years old when the interview was conducted, was educated in Catalonia, and has completed higher education. He points out, however, that the expression is something he has heard at home and that his mother uses it more than he does. None of the other participants use this expression, let alone recognize it.

The fact that these expressions do not have an equivalent in Catalan does not necessarily mean that they are not categorized by Catalan speakers. Arbub $n$ tiymas and addiy $n$ taddaxt label references possibly categorized by Catalan speakers (Ferrerós, 2015). However, akmmar refers to a segment clearly not categorized by Catalan speakers (Ferrerós, 2015, p. 399).

Terms in Catalan without an Equivalent in Amazigh. The referents selected here have the peculiarity of not being labelled in Amazigh: hence the informants do not mention them before the semistructured interview, and evidently do not appear in any of the previous psycholinguistic tasks.

Table 2

Terms in Catalan without an equivalent in Amazigh

\begin{tabular}{lll}
\hline parpella (Cat.) & acddis $\mathrm{n}$ tiḍt (?) (Am.) lit. 'belly of the eye' & 'eyelid' \\
paladar (Cat.) & acrur uqmmum (?) (Am.) lit. 'back of the mouth' & 'palate' \\
\hline
\end{tabular}

The words parpella 'eyelid' and paladar 'palate' in Catalan have no equivalent in Amazigh. This does not mean, like in some of the cases set out in the section Terms in Amazigh without an equivalent in Catalan, that they are not categorized in Amazigh. In a situation of metalinguistic reflection, the speakers immediately understand which body parts are being referred to. Sarrionandía and Ibáñez (2007 [1949]), in their Spanish-Amazigh dictionary, suggest the nominal expressions that appear in the table as translations of Spanish words párpado 'eyelid' and paladar 'palate,' probably to match the categorical segments of Spanish with those in Amazigh. The speakers interviewed analyze and understand these expressions, but explain that they do not use them or see them as fixed expressions in their L1. Some of the younger participants say they sometimes use the word in Catalan or Spanish when they speak Amazigh. In other cases, they label 'eyelid' with the word abliwn 'eyelashes.' Regarding acrur uqmmum, one of the younger speakers affirmed that he believes that it is an expression used by the elderly, although no elderly participants in the sample recognized it. 


\section{Issues of Polysemy or Vagueness with Anatomical References}

Vague or polysemic Amazigh words. The following shows cases in which there are more words in Catalan than Amazigh to refer to a given part of the body:

Table 3

Vague or polysemic Amazigh words

\begin{tabular}{llll}
\hline Amazigh & Meaning & Catalan & Meaning \\
\hline tagarjumt & 'tube that goes through the throat' & $\begin{array}{l}\text { esòfag } \\
\text { faringe }\end{array}$ & $\begin{array}{l}\text { 'oesophagus' } \\
\text { 'pharynx' } \\
\end{array}$ \\
& & laringe & 'larynx' \\
& mà & 'hand' \\
afus & braç & 'arm' \\
& & peu & 'foot' \\
aḍar & 'leg' 'foot' & cama & 'leg' \\
& & &
\end{tabular}

The word tagarjumt 'tube that goes through the neck' is known to all Amazigh speakers interviewed to also refer to 'throat' and 'pharynx, larynx, and oesophagus.' They do not mention specific words for each of these references and, when they have to distinguish them, they refer to what is used to breathe and what is used to eat. In Catalan, despite the fact that there are three terms to refer to it, speakers often confuse their use because they are recently introduced and rather specific terms. The usual term in Catalan to refer to these internal body parts is coll, which is also used to refer to the corresponding external part of the neck.

Unlike the referents until this point, the words afus 'hand/arm' and adar 'leg/foot' do appear in the psycholinguistic tasks previous to the semistructured interview. In the list task afus appears in all 14 cases, whereas adar appears in 12 of them. Thus, these are body parts considered relevant to the interviewed informants. Furthermore, these are body parts included in the body coloring task. In the case of afus, in six cases the informants paint only the hand: all the participants of the group that lived longer in Catalonia than in Morocco and one respondent of the last group. The other participants color the whole upper limb, including the hand. Regard adar, all respondents color the leg segment between knee and foot, except two participants of the first group, who only color the foot.

The word afus in Amazigh refers to 'hand' and 'arm.' As previously explained, this is the segment colored by most participants in the two last groups in the body coloring task. But Amazigh speakers of the first group, who spent longer in Catalonia than in Morocco, in a situation of metalinguistic reflection, 
tend to categorize and label these body parts in the same way as in Catalan, as seen in the results of the coloring task. In the interview, when asked, they say that 'arm' is called ayil (a word that never appears in the list task) and 'hand' afus. However, in more spontaneous situations, they never mention ayil, they always talk about afus to refer to both 'arm' and 'hand.' The informants that spent longer in Morocco than in Catalonia, on the other hand, only mention the word afus for these two body parts ('hand' and 'arm'), just like the participants living in Morocco. The latter group explains that ayil has a meaning close to 'shoulder.'

The situation is not similar for the lower limbs: Amazigh speakers only mention the word adar to refer to the words for leg and foot in Catalan. It is also noted that in the body coloring task it is more often considered the name of a referent including the foot too.

Vague or polysemic Catalan words. The following shows examples contrary those above:

Table 4

Vague or polysemic Catalan words

\begin{tabular}{llll}
\hline Amazigh & Meaning & Catalan & Meaning \\
\hline izaggwn & 'armpit and pubic hair' & pèl & 'body hair' \\
izuțțn / acaer & 'body hair, except armpit and pubic hair' & & \\
ijiman & 'sides of the neck' & clatell / 'nape' \\
taḥbut n ijiman & 'nape cavity' & nuca & \\
stumagu & 'stomach' & estómac & 'stomach' \\
taramant & 'internal stomach' & & \\
\hline
\end{tabular}

In Amazigh, different words are used to label 'body hair' and 'armpit and pubic hair.' Although armpit and pubic hair are not categorized together in Catalan, they are considered different from leg or arm hair by Catalan speakers. Therefore, the categorical segmentation is not as different as the lexicon suggests (Ferrerós, 2015, p. 399). The words clatell and nuca in Catalan refer to a segment that, for the amazighs of the latter group, older people, are two different categories called ijiman 'sides of the neck' and tahbut $n$ ijiman 'nape cavity.' In Catalan, the word stomach does not make any distinction between the internal and external part of this organ, but refers to the whole organ in itself. In Riffian Amazigh, there is a word referring to the outside, stumagu, which is a loan word from Spanish, as well as a specific word referring to the internal part, taramant.

The Amazigh words here presented never appear in the list task: they are perceptively not very relevant body parts. Only the ones referring to the nape 
(ijiman and tahbut $n$ ijiman) appear in the coloring task: the informants of the first group, except two of them, do not recognize these words and do not paint their referents.

The three cases we have presented are similar: the participants' responses suggest that the distinctions shown in the Amazigh words are maintained by the speakers of the last group: the ones that spent longer in Morocco than in Catalonia. Regarding the other participants, we have observed the following: first, they extend the use of the word izuttn or acasr to refer to all body hair. Second, apart from two participants, and as aforementioned in the previous paragraph, they do not recognize the word tahbut $n$ ijiman. In the last case, we have observed that the word taramant is only recognized by the two oldest participants, belonging to the last group. Moreover, the speakers who still reside in Morocco do not recognize this word either.

We have also found cases in which there are words in the two languages that are used to label more than one reference, but whose meanings do not coincide:

Table 5

Amazigh and Catalan vague or polysemic words

\begin{tabular}{llll}
\hline Amazigh & Meaning & Catalan & Meaning \\
\hline arrimt & 'skin' 'body' & cos & 'body' 'trunk' \\
\hline
\end{tabular}

In Amazigh, the first partonomic level is called arrimt 'body', but the meaning first mentioned by the participants of the last group, who are older people, is 'skin of the entire human body.' Three of the Amazigh speakers who have had greater contact with Catalan and two participants who have spent the same time in Catalonia as Morocco at the time of being interviewed spontaneously state that arrimt can refer to both 'skin' and 'body,' but then they correct themselves and give different labels to each category. They often use arrimt for 'skin of the entire body' and borrow from Arabic to designate 'body': ljsdt or ddat. In Catalan, the prototypical meaning of cos is 'body,' and an associated meaning is 'trunk.' None of the Amazigh participants use arrimt to refer to 'trunk,' as in Catalan with the word cos.

\section{Differences in the Use of Non-literal Meanings of Polysemic Words for Body Parts: The Example of 'Heart'}

Both in Catalan and in Amazigh, the word for 'heart' has many associated meanings. The theory of conceptual metaphor and metonymy (Lakoff \& Johnson, 1999; 2008) focuses on the study of non-literal expressions in language, that is, the study of the non-prototypical meanings of words. Metaphor is a cognitive process that correlates two different domains. Conceptual meta- 
phors are expressed in language with metaphorical expressions in which the vocabulary of a source domain is used, but the meaning is found in a different domain, the meta domain. Metonymy is a similar cognitive process but it correlates elements within the same conceptual domain. According to Barcelona (2002, pp. 14-15), metonymy responds to a general pattern, which refers to relationships such as WHOLE FOR PART, PART FOR WHOLE, etc.

Regarding the word for 'heart' in both languages, most non-literal meanings coincide and we will not list them here (HEART FOR THE ADJACENT AREA, HEART FOR SINCERITY, HEART FOR EMOTIONS AND FEELINGS, etc.). We have only listed one that coincides (HEART IS SOMETHING LOVED) because it presents certain differences between the two languages. All information obtained for this section is sourced from the semi-structured interview: it did not appear in the psycholinguistic tasks, which were exclusively focused on obtaining results about literal meanings.

Table 6

Metaphoric and metonymic linguistic expressions with ul and cor 'heart'

\begin{tabular}{|c|c|c|}
\hline Catalan & Amazigh & Semantic relationship \\
\hline $\begin{array}{l}\text { Bravery } \\
\text { Fer el cor fort 'make the } \\
\text { heart strong (lit.), give it } \\
\text { all your heart' }\end{array}$ & & Metonymy: PART FOR FUNCTION ${ }^{a}$ \\
\hline $\begin{array}{l}\text { Memory } \\
\text { Aprendre de cor 'learn of } \\
\text { heart (lit), learn by heart' }\end{array}$ & & Metonymy: PART FOR FUNCTION \\
\hline $\begin{array}{l}\text { Object that looks like it } \\
\text { cor de bou (mol-lusc) 'ox } \\
\text { heart (lit.), bivalve mollusc' }\end{array}$ & & Metaphor: HEART IS OBJECT \\
\hline \multirow[t]{3}{*}{$\begin{array}{l}\text { Carta de cors } \\
\text { 'heart card' }\end{array}$} & & $\begin{array}{l}\text { Metonymy } \\
\text { (derived from HEART IS OBJECT) }\end{array}$ \\
\hline & $\begin{array}{l}\text { Individual } \\
\text { Nniy-as dg wul-inu } \\
\text { 'I told my heart (lit.), I said } \\
\text { to myself' }\end{array}$ & Metonymy: PART FOR WHOLE \\
\hline & $\begin{array}{l}\text { Enthusiasm, desire, drive } \\
\text { s wul } \\
\text { 'with heart (lit.), with } \\
\text { enthusiasm' }\end{array}$ & Metonymy: PART FOR FUNCTION \\
\hline $\begin{array}{l}\text { Something loved } \\
\text { el cor d'una mare } \\
\text { 'the heart of a mother } \\
\text { (lit.), a mother's love' }\end{array}$ & $\begin{array}{l}\text { Something loved } \\
\text { ul inu } \\
\text { 'my heart (lit.), my love, } \\
\text { dear' }\end{array}$ & $\begin{array}{l}\text { Metaphor: HEART IS SOMETHING } \\
\text { LOVED } \\
\text { (derived from PART FOR } \\
\text { FUNCTION) }\end{array}$ \\
\hline
\end{tabular}

a For historical reasons, because emotions and personality traits in the past would have been to the heart in a literal manner, some metaphorical expressions have been classified as metonymic (part for function). It should be noted that the fact that the meanings associated with 'heart' in both languages are related to emotions, feelings, and personality traits is due not only to cultural factors but also to the phenomenon of embodiment: one's heartbeat can vary in terms of the emotion they are experiencing, and this can influence the existence of metaphors and conceptual metonyms. 
As seen in Table 6, some examples of metonymy have been found only in Amazigh or only in Catalan. In their language, Amazigh speakers do not use linguistic expressions that specify the metonymy HEART FOR BRAVERY and HEART FOR MEMORY as with Catalan. In fact, they do not know them in Catalan either, except for two participants between 30 and 45 years of age, one of whom has spent more time in Catalonia than Morocco and the other who has spent the same amount of time in both places. However, they do know and use the expressions that determine the metonymy HEART FOR INDIVIDUAL and HEART FOR ENTHUSIASM, both typical in Amazigh.

Regarding the metaphor in Catalan HEART IS OBJECT (which is similar in form), which does not exist in Amazigh, it is worth noting that the younger Amazigh speakers who have been educated in Catalonia use this expression in their L1, in some cases using the words cor or corazón and inserting them into Amazigh speech instead of using $u l$. Conversely, older Amazigh speakers who have spent more time in Morocco do not recognize it and do not recognize the conventionalized image the heart represents. This image would not be called $u l$ by younger Amazigh speakers, but rather cor or corazón ('heart,' in Catalan and Spanish) even when speaking Amazigh.

There is a shared meaning that presents certain differences: the metaphor HEART IS SOMETHING LOVED. In Amazigh, the word $u l$ 'heart' is used by people who love each other, but if that feeling is very intense, especially from parents towards their children, the word for 'liver' is used: tasa. In Catalan, on the other hand, fetge, the word for liver, does not have this meaning, although expressions exist that are related to emotions and personality traits using the word liver. Thus, the words for 'heart' refer to 'feelings' in both languages, but the distribution of feelings between heart and the liver is different. The Amazigh speakers who have spent the most time living in Catalonia and who have been educated there use the word $u l$ 'heart' with the same meanings as the equivalent word in Catalan regarding feelings and emotions. They state that they would use $u l$-inu 'my heart' for their children rather than tasa-inu 'my liver,' which is the expression that would be used by the other speakers in the sample.

\section{Cases with Differences Related to the Use and Knowledge of Words}

The younger Amazigh speakers who have been educated in Catalonia and who have spent more time there have difficulty understanding certain words. In general, these speakers easily recall the words for 'eyes,' 'mouth,' 'head,' 'face,' 'belly,' 'back,' 'hand/arm,' 'leg/foot,' 'heart,' and 'liver,' but have a hard time remembering words that refer, for example, to 'elbow,' 'knee,' 'spleen,' and so on. Actually, the words labelling these references never appear on the list 
task. However, such words are recognized when they are spoken, except by the two youngest Amazigh speakers. The same applies for synonyms of the most common words that designate the body parts that we have mentioned. Thus, for example, although the participants regularly use aymbub for 'face,' they did not remember, and in some cases they did not recognize, the synonym $u d m$. The speakers of the last group have more difficulty recalling these synonyms and using them, but they understand them when they are mentioned.

\section{Discussion}

\section{The Various Effects of the Influence of L2 on L1}

Pavlenko (2000) points out that research on the influence and transfer between L1 and L2 has focused on this sense of interference and the description of these phenomena, taking into account the different components of grammar, lexicon, semantics, pragmatics, and rhetoric. The author proposes a unitary framework for the study of transfers that can be applied to the study of any type of transfer or influence between two languages, and distinguishes some phenomena that must be taken into account (see the end of section The Transfer of L2 to L1 with Bilingual or Multilingual Speakers). ${ }^{4}$

The first one refers to the use of borrowing, that is to say, the addition of elements from L2 to L1. In our study we found two types of loan words: some old ones, borrowed from Romance languages that entered the language in colonial times. We will not take them into account here, as they are also part of the language spoken in the territory of origin. We will take into account borrowing in terms of loan words that have been produced through contact with Catalan in the context of migration. We have seen situations in which the L2 labels more references than the L1, such as 'eyelid' or 'palate,', which are not named in Amazigh. The youngest speakers and those who have been educated in Catalonia, in these cases, often use the Catalan or Spanish word (parpella, párpado) when speaking in Amazigh to refer to this part of the body.

Although these two body parts are not labelled in Amazigh, it seems that they are categorized. This leads participants, on the one hand, to use loan words

\footnotetext{
${ }^{4}$ Here it must be remembered that all the participants in the sample are plurilingual (they can speak in Arabic, French, or Spanish, too). It must be noted that in Morocco it is difficult to find monolingual Amazighs and in Catalonia there are no monolingual Catalans. Being both languages subordinated to a dominant language, it was not possible to find participants speaking Amazigh and Catalan exclusively. Deeper studies should be focused on distinguishing, as thoroughly as possible, the influences of the different spoken by each participant.
} 
to refer to them (especially when they have had more contact with the L2) and, on the other hand, to recognize the expressions given by certain bilingual dictionaries that older Amazigh speakers have never used, like the syntagmatic compound that literally means 'belly of the eye.' The participant's recognition of compounds owes to the fact the body part is categorized in Amazigh, but also because it is named in Catalan. The speakers interviewed who have not left Morocco and who do not speak languages other than Amazigh and Moroccan Arabic in their daily lives do not interpret this expression so readily. ${ }^{5}$ This involves a case of crosslinguistic influence, but categorization is similar in both languages.

Furthermore, we have observed that, when referring to the metaphorical meaning of heart is object in Amazigh, borrowing from Catalan or Spanish is sometimes used to refer to it. Cor or corazón is used to label the typical drawing of a heart shape. The participants state that they would never use $u l$ to refer to it, as there are no linguistic expressions in Amazigh derived from the metaphor heart is object. Therefore, in this case, apart from the crosslinguistic influence that we have described, there would be a transfer related to the processes of categorization and conceptualization shown by the languages involved.

The second phenomenon mentioned by Pavlenko (2000) is restructuring, that is, the incorporation of elements from L2 to L1 that result in changes, substitutions, or partial displacements. These partial displacements may result in a change of categorical prototypes or a change of boundaries between categories. If we take an example from the results we have shown, we see that there is a word for 'hand' and a word for 'arm' in Catalan yet, in Amazigh, the word afus is polysemic and refers to both categories. Although in a spontaneous situation all the speakers use afus to refer to the upper limb, when doing a metalinguistic reflection or in psycholinguistic tests such as the body coloring task, the speakers of the first group correct themselves and state that afus labels 'hand' and that the word ayil (which in some varieties of Riffian Amazigh means 'forearm' or 'arm' and even 'shoulder' in rarely used cases) refers to 'arm.' The fact that it has been demonstrated that, in languages in which the same word is used for 'hand' and for 'arm,' the word is polysemic (see, for example, Brown, 2013; Wierzbicka, 2007) leads us to the assertion that it does not involve a case of categorical transfer but rather of crosslinguistic influence.

Let us now look at the apparent similarity between the word afus 'hand, arm' and the word adar 'foot, leg.' Using analogous examples in Polish, Wierzbicka (2007, p. 30) shows that the word referring to 'hand' and 'arm' is polysemic, whereas the word referring to lower limbs is not. Furthermore, we can see that, with respect to the lower limbs, no speaker specifically uses the word

${ }^{5}$ In Moroccan Arabic, the word šfar means 'eyelash' and 'eyelid.' On the other hand, Moscoso (2005) lists the syntagmatic compound la-g̣ta $d$ el-Gaynin, lit. 'the lid of the eye,' as a translation for 'eyelid.' 
adar for 'foot' and looks for another one for 'leg' like they did with the upper limbs. This suggests that linguistic transfer studies of bilingual speakers give clues to the discussion on polysemy and vagueness (see, for example, Enfield, Majid, \& Van Staden, 2006; Koptjevskaja-Tamm, Rakhilina, \& Vanhove, 2016; Wierzbicka, 2007): there is more linguistic transfer when the word is polysemic and less when it is vague, because that would imply a recategorization.

The word for 'body' involves another case of restructuring. In Catalan, the word cos refers to 'body' and 'trunk,' while in Amazigh, arrimt means 'skin of the entire body' and 'body.' Amazigh speakers who have spent the most time in Catalonia, despite knowing the word arrimt has these two meanings, state that they use it for 'skin' and they use a borrowing from Arabic (ljsdt or ddat) for 'body.' The fact that they use an Arabic loan word shows that interference does not likely come from Catalan. In any case, the restructuring of the semantic paradigm is a conceptual transfer. It is worth noting that the case of 'body' relates to important issues in semantic and lexicon studies of anatomy: there is a discussion among researchers about whether this partonomic level 0 can be designated with a loan word or not (see Enfield, Majid \& Van Staden, 2006; Wierzbicka, 2007). We see that, at least as regards cases with bilingual speakers, and due to linguistic restructuring, it is named with a loan word from Arabic, the dominant language.

Pavlenko (2000) also mentions the phenomenon of convergence, through which the structures of the two languages converge into an intermediate structure, different from each individual language. We have found a case of convergence with two concepts in one, different from the two concepts of each linguistic community involved. We have seen that Amazigh speakers who specifically use the word afus for 'hand' use the word ayil for 'arm.' However, they affirm that this word, used in this way, has nuanced semantics focusing on the upper part of the upper limb. That is to say, ayil, as they use the word when saying afus specifically for 'hand,' coincides neither with the actual Amazigh meaning ('shoulder') nor with the meaning of the Catalan word for arm. This phenomenon of convergence shows that there has been a restructuring of the conceptual system of the L1.

The results of our study also show cases of displacement, another of the phenomena mentioned by Pavlenko (2000), that is, changes in certain L1 structures that approximate L2 structures. In our case, we have observed semantic displacements for which the lexical pieces of the L1 get meaning added to them with partially equivalent polysemic words from the L2. The words for 'heart' in both languages are highly polysemic. We have observed two remarkable phenomena, both from the speakers of the first group who have been educated in Catalonia: on the one hand, the metaphor heart is object is displaced to Amazigh and, as we have seen, in these cases the Catalan or Spanish word is inserted into Amazigh speech. On the other hand, we have also seen that one 
of the meanings of the word heart in Catalan is 'something loved.' In Amazigh, $u l$ also has this meaning, except when children are the 'something loved,' in which case tasa 'liver' is used. Some of the younger speakers, however, also attribute it to 'heart' in their language as occurs in Catalan. These cases of displacement show that there have been influences of the categorization system from L2 to L1, in this case related to the non-literal meanings of a word.

The last phenomenon mentioned by Pavlenko (2000) refers to the erosion of the L1, that is to say, the loss or inability to produce some elements of the L1 due to the influence of the L2. When there are terms in Amazigh that do not have an equivalent in Catalan, we have observed that they are often only used by older Amazigh speakers, the participants of the last group. Some younger speakers recognize such terms, but state that this is because they have heard elderly people use them. The participants who have lived in Catalonia longest (Ferrerós, 2015), do seem to categorize, for example, 'tooth growing too close to another tooth' even though they do not have a word to label it. There would be no recategorization in this case. However, there would be cases in which they do not categorize an entity labelled in Amazigh, such as akmmar 'lower part of the face.'

These younger participants are aware that they do not speak the same language as their older relatives. That is why, for example, when asked about expressions that are not typical of the L1 but which some dictionaries list, such as what literally means 'back of the mouth' ('palate'), some claim to believe that these expressions are used by the elderly, although they have never been heard at home because they are not native to Amazigh.

In the same way, the two youngest speakers, who belong to the first group, say they have never heard the word arrimt 'body' even though it is a word that belongs to their language. They have also lost some distinctions that Amazigh words convey which do not have equivalents in Catalan, and there has been a deviation of categorial boundaries. For example, in the case of izaggwn 'armpit and pubic hair' and izutth 'body hair except armpit and pubic hair', they extend the use of izuttn, which ends up equivalent to the word hair in Catalan, and they have lost the use of the word izaggwn. They have also lost the word taramant 'inner stomach' and only use stumagu 'stomach.' In the latter case, however, it is possible that this is also due to the fact that they live in an urban environment: the three Amazigh speakers living in Morocco, in the city of Lhusima, do not use the word taramant either. Therefore, it is important to take into account that there are several factors that can cause these linguistic changes aside from the attrition of the L1 within the context of migration.

At this point it is worth highlighting that there is a difference related to the participants' age and length of time spent in Catalonia: when the speakers are younger and have spent more time in Catalonia than Morocco, and speak a different sort of Amazigh than what is spoken in their territory of origin, it is 
possible that their particular language systems have not suffered attrition or that there has not been a transfer in their particular conceptual systems. However, we have found cases of particular language systems that have clearly been eroded by contact with the L2. Some older Amazigh speakers who have lived approximately the same time in Morocco as Catalonia claim that it is hard for them to remember certain words for labelling less relevant body parts (taking into account the data obtained through the listing task). Nor do they remember less frequently used synonyms of words that refer to more relevant body parts (for example $u d m$, which is used less frequently than aymbub for 'face'). In fact, an important aspect in lexicon and semantics studies within the context of bilingualism or multilingualism is the aspect regarding the difficulty of lexical recovery. Authors who have researched this issue include De Bot and Stoessel (2000), Latomaa (1998), and Oshtain and Barzilay (1991). These studies show that not only do such late bilinguals speak with more gestures, but they also have difficulty finding words from their L1. When speakers have spent more time in contact with the L2, we observe greater attrition of the L1. Jessner (2003, p. 238) explains, in fact, that linguistic erosion is "a gradual process of information decay that is dependent on time."

One of the questions posed in bilingualism studies is whether such speakers have two systems of conceptual representation (one for each language) or a single underlying system for both languages. Otheguy and Garcia (1993) affirm that late bilinguals have systems of coexisting conceptual representation underlying the use of both languages. Conversely, other studies show evidence of conceptual changes. Based on the results of our research, it appears that the youngest speakers, who spent longer in Catalonia than in Morocco, have two very convergent underlying conceptual systems, which is why we have pointed out that phenomena such as linguistic attrition do not occur in the particular language of these specific speakers. Rather, we can only speak of erosion if we compare their language use with that of other speakers. In contrast, speakers who have been exposed to the L2 at an older age seem to have two underlying conceptual, coexisting, and less convergent representation systems, although with mutual influences. Some available studies on conceptual transfer show that conceptual representations are subject to changes in adulthood (Jarvis, 2011; Pavlenko, 1999, 2000; Pavlenko \& Jarvis, 2000).

\section{Extralinguistic Factors That Affect the Influence of the L2 on the L1}

One extralinguistic factor that affects the influence of the L2 on the L1 is the prestige that speakers attribute to one of the two languages (Pavlenko, 2000; Weinreich, 1953). Weinreich (1953), for example, shows that more loan words from the L2 are used if they seem to have greater prestige, to make 
the speaker's familiarity with the language deemed more prestigious evident. In this paper, we have shown that prestige not only results in borrowing, but also other cases of linguistic transfer, including conceptual transfer. Within the context of migration, the language of the receiving country is considered more prestigious. In this case, both languages are minoritized languages, but Catalan has a much greater public presence than Amazigh. Thus, when Catalan labels more parts of a given reference, or when it presents more categories, the speakers of the first group, at least in a situation of metalinguistic reflection, make the L1 categorization and labelling coincide with those of the L2. This, however, is also related to the fact that, being accustomed to speaking Catalan or Spanish, they feel the need to designate a reference in their native language for which the latter has no label or category.

Another important aspect to take into account is the age of the participants and the level and type of contact which late bilinguals may have with L2 speakers. Through the analysis of the results, we have shown that almost all the crosslinguistic transfers and influences observed and most cases of transfers related to categorization and conceptualization occur with the speakers of the first group: younger speakers who have been educated in Catalonia.

One more extralinguistic factor we think should be taken into account is related to the choice of methodology used (Ferrerós, 2016). Throughout the presentation of the results from this study, we have already observed how participants might give different answers depending on whether they are in a situation of spontaneous conversation or metalinguistic reflection. But there are other phenomena that must be taken into account, such as the semantic domains analyzed in any given research. Many studies have described crosslinguistic transfers taking into account semantic fields related to culture and environmental factors, which is why numerous cases of linguistic transfer, including conceptual, have been noted. In contrast, this paper is based on data from a basic semantic domain: that of body parts. There are certain words and meanings related to a reference that are the same for everyone in every location, but which are categorized and named in different ways.

\section{Conclusions}

With the analysis of the results from this study, we have determined the cases in which there have been crosslinguistic influences and influences between different ways of categorizing and conceptualizing reality. Thus, when loan words from the L2 are used, we have determined that there is recategorization if a borrowing serves to label a body part not categorized in L1, which 
can also be used to label a categorized yet unnamed body part thus becoming adopted more easily. The cases of displacement and restructuring also show diverse results: in the case of the polysemic words in the L1 that are equivalent to two different words in the L2, if there has been crosslinguistic influence that has caused the polysemic word from the L1 to become specified for just one of its meanings, there is no recategorization. However, if the L1 word was vague and the L2 influence led to specifying when using a meaning from the equivalent L2 word, there is recategorization. We have not found any cases of this second type. Thus, we have shown how bilingual studies can provide new data to the debate on the distinction between phenomena of polysemy and semantic vagueness. We have also found data that respond to the phenomenon of convergence, that is, we have detected categories or concepts that are different from those shown by the two languages involved and, therefore, the existence of this phenomenon shows a conceptual restructuring. Finally, with regard to attrition, we have observed that the speech of the oldest speakers and those who have had greater, more intense contact with the L1 in their youth has undergone erosion. With these participants, we have indeed seen cases of recategorization.

\section{References}

Andersen, E. S. (1978). Lexical universals of body-part terminology. In J. H. Greenberg (Ed.), Universals of human language (pp. 335-367). Stanford: Stanford University Press.

Aveledo, F., \& Athanasopoulos, P. (2016). Second language influence on first language motion event encoding and categorization in Spanish-speaking children learning L2 English. International Journal of Bilingualism, 20(4), 403-420.

Barcelona, A. (2002). Introduction. The cognitive theory of metaphor and metonymy. In A. Barcelona (Ed.), Metaphor and metonymy at the crossroads (pp. 1-28). Berlin: Mouton de Gruyter.

Barrieras, M. (2013). La cruïlla del multilingüisme: les llengües dels catalans al segle xxi. Divèrsia: Revista de la Càtedra sobre Diversitat Social de la Universitat Pompeu Fabra, 3, 2-37.

Brown, C. H. (1976). General principles of human anatomical partonomy and speculations on the growth of partonomic nomenclature. American Ethnologist, 3(3), 400-424.

Brown, C. H. (2013). Hand and arm. In M. S. Dryer \& M. Haspelmath (Eds). The world atlas of language structures online. Leipzig: Max Planck Institute for Evolutionary Anthropology. Accessed August 10, 2019. Retrieved from: http://wals.info/chapter/129

Bylund, E. \& Athanasopoulos, P. (2014). Linguistic relativity in SLA: Toward a new research program. Language learning, 64(4), 952-985.

Bylund, E. \& Jarvis, S. (2011). L2 effects on L1 event conceptualization. Bilingualism: Language and Cognition, 14(1), 47-59.

Cadierno, T. \& Ruiz, L. (2006). Motion events in Spanish L2 acquisition. Annual review of cognitive linguistics, 4(1), 183-216. 
Cook, V. J. (2003). The changing L1 in the L2 user's mind. In V. Cook (Ed.), Effects of the second language on the first (pp. 1-8). Clevedon: Multilingual Matters.

De Bot, K. \& Stoessel, S. (2000). In search of yesterday's words: Reactivating a long-forgotten language. Applied Linguistics, 21(3), 333-353.

Enfield, N. J. (2006). Elicitation guide on parts of the body. In A. Majid, N. J. Enfield, \& M. Van Staden (Eds.), Parts of the body: Cross-linguistic categorisation (Special Issue). Language Sciences, 28, 148-157.

Enfield, N. J., Majid, A., \& Van Staden, M. (2006). Cross-linguistic categorisation of the body: Introduction. In A. Majid, N. J. Enfield, \& M. Van Staden (Eds.), Parts of the body: Crosslinguistic categorisation (Special Issue). Language Sciences, 28, 137-147.

Ferrerós, C. (2015). Categorització semàntica de les parts del cos en català i en amazic: un estudi comparatiu. Unpublished doctoral dissertation, Universitat de Girona.

Ferrerós, C. (2016). Variació intralingüística en la categorització i l'etiquetatge de les parts del cos en català: una reflexió metodològica. Estudis Romànics, 38, 7-31.

Grosjean, F. (1998). Studying bilinguals: Methodological and conceptual issues. Bilingualism: Language and cognition, 1(2), 131-149.

Ibarretxe-Antuñano, I. (1999). Polysemy and metaphor in perception verbs: A cross-linguistic study. Unpublished doctoral dissertation: Edimburg University. Accessed February 21, 2017. Retrieved from: http://www.unizar.es/linguisticageneral/articulos/Ibarretxe-PhD-Thesis-99. pdf

Ibarretxe-Antuñano, I. (2010). Lexicografía y Lingüística Cognitiva. Revista Española de Lingüistica Aplicada, 23, 195-213.

Ibáñez, E. (1949). Diccionario Rifeño-Español (etimológico). Madrid: Imprenta y Editorial Maestre). Melilla- Barcelona:UNED-Edicions Bellaterra.

Jarvis, S. (2011). Conceptual transfer: Crosslinguistic effects in categorization and construal. Bilingualism: Language and cognition, 14(1), 1-8.

Jarvis, S. (2016). Clarifying the scope of conceptual transfer. Language Learning, 66(3), 608-635.

Jarvis, S., \& Pavlenko, A. (2008). Crosslinguistic influence in language and cognition. New York: Routledge.

Jessner, U. (2003). The nature of cross-linguistic interaction in the multilingual system. In J. Cenoz, B. Hufeisen, \& U. Jessner (Eds.), The multilingual lexicon (pp. 45-55). Dodrecht: Kluwer Academic Publishers.

Koch, P. (2005). Aspects cognitifs d'une typologie lexicale synchronique. Les hierarchies conceptuelles en français et dans d'autres langues. Langue française, 145, 11-33.

Koptjevskaja-Tamm, M. Rakhilina, E., \& Vanhove, M. (2016). The semantics of lexical typology. In N. Riemer (Ed.), The Routledge handbook of semantics (pp. 434-454). New York: Routledge.

Lakoff, G. (1987). Women, fire and dangerous things: What categories reveal about the mind. Chicago: University Chicago Press.

Lakoff, G. \& Johnson, M. (1999). Philosophy in the Flesh: The Embodied Mind and Its Challenge to Western Though. New York: Basic Books.

Lakoff, G. \& Johnson, M. (2008). Metaphors we live by. Chicago: University of Chicago Press.

Latomaa, S. (1998). English in contact with "the most difficult language in the world": The linguistic situation of Americans living in Finland. International Journal of the Sociology of Language, 133(1), 51-72.

Lucy, J. A. (2016). Recent advances in the study of linguistic relativity in historical context: A critical assessment. Language Learning, 66(3), 487-515.

Moscoso, F. (2005). Diccionario español-árabe marroquí. Dirección General de Coordinación de Políticas Migratorias. Consejería de Gobernación. Junta de Andalucía. Accessed March 
17, 2019. Retrieved from http://www.juntadeandalucia.es/export/drupaljda/diccionario_espanol-arabe_marroqui.pdf

Múrcia, C. \& Zenia, S. (2015). Diccionari català-amazic / amazic-català. msmun awal tamazivt-

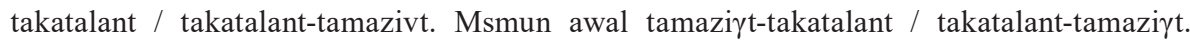
Barcelona: Llibres de l'Índex.

Nait-Zerrad, K. (1997). Dictionnaire des raciness berbères (formes attestées). Vol. I. ParisLouvain: Éditions Peeters.

Naït-Zerrad, K. (1999). Dictionnaire des raciness berbères (formes attestées). Vol. II. ParisLouvain: Éditions Peeters.

Naït-Zerrad, K. (2002). Dictionnaire des raciness berbères (formes attestées). Vol. III. ParisLouvain: Éditions Peeters.

Olshtain, E., \& Barzilay, M. (1991). 10 Lexical retrieval difficulties in adult language attrition. In H .W. Seliger \& R. M. Vago (Eds.), First language attrition (pp. 139-150). Cambridge: Cambridge University Press.

Otheguy, R., \& Garcia, O. (1993). Convergent conceptualizations as predictors of degree of contact in US Spanish. In A. Roca \& J. M. Lipski (Eds.), Spanish in the United States: Linguistic contact and diversity (pp. 135-154). Berlin: Mouton de Gruyter.

Park, H. I. (2019). How do Korean-English bilinguals speak and think about motion events? Evidence from verbal and non-verbal tasks. Bilingualism: Language and cognition, $1-17$.

Pavlenko, A. (2000). L2 influence on L1 in late bilingualism. Issues in Applied Linguistics, $11(2), 175-205$.

Pavlenko, A. (2014). The bilingual mind: And what it tells us about language and thought. Cambridge: Cambridge University Press.

Rampton, B. (2017). Crossing: Language and ethnicity among adolescents. New York: Routledge.

Rosch, E. (1973). Natural categories. Cognitive psychology, 4(3), 328-350.

Rosch, E. (1978). Principles of Categorization. In E. Rosch \& B. B. Lloyd (Eds.), Cognition and categorization (pp. 27-48). Hillsdale: Lawrence Erlbaum.

Sarrionandía, P. H., \& Ibáñez Robledo, E. (2007). Diccionarios Español-Rifeño y RifeñoEspañol (facsímile of Ibáñez, E. (1944)). Diccionario Español-Rifeño. Madrid: Ediciones de la revista "Verdad y Vida."

Serhoual, M. (2002). Dictionnaire tarifit-français. Unpublished doctoral dissertation, Université Abdelmalek Essaâdi, Tétouan.

Slobin, D. I. (1996). From "thought and language" to "thinking for speaking." In J. J. Gumperz \& S. C. Levinson (Eds.), Studies in the social and cultural foundations of languages, 17. Rethinking linguistic relativity (pp. 70-96). Cambridge: Cambridge University Press.

Van Staden, M., \& Majid, A. (2006). Body colouring task. In A. Majid, N. J. Enfield, \& M. Van Staden (Eds.), Parts of the body: Cross-linguistic categorisation (Special Issue). Language Sciences, 28, 158-161.

Weinreich, U. (1953). Languages in contact, findings and problems. New York: Linguistic Circle of New York.

Whorf, B. L. (1956). Language, thought and reality. Selected writings of Benjamin Lee Whorf. Cambridge: Technology Press of Massachusetts Institute of Technology.

Wierzbicka, A. (2007). Bodies and their parts: A NSM approach to semantic typology, Language Sciences, 29, 14-65. 
Carla Ferrerós Pagès

\title{
Konzeptueller und sprachlicher Transfer von L2 (Katalanisch) zu L1 (Amazigh) im Kontext der Migration
}

\begin{abstract}
Zusammenfassung
Der vorliegende Beitrag konzentriert sich auf die Analyse der lexikalischen und semantischen Einflüsse von L2 (Katalanisch) auf L1 (Amazigh) in einem elementaren semantischen Feld: Körperteile. Ausgehend von der Beobachtung, dass die Probanden Unterschiede in L1Gebrauch aufweisen, die mit der Dauer ihres Kontakts mit dem Katalanischen zusammenhängen, wird analysiert und erörtert, ob die genannten Unterschiede die Folge eines Transfers aus dem konzeptuellen System von L2 sind. Es ist eine qualitative Studie mit einer Stichprobe von 14 Probanden, deren L1 Amazigh ist und die in Katalonien leben. Die Ergebnisse zeigen, dass es Fälle von semantischem und konzeptuellem Einfluss gibt, wenn auch in geringerem Maße als in anderen Studien, die keine Daten aus elementaren semantischen Feldern analysieren. Darüber hinaus wird darauf hingewiesen, dass es außersprachliche Faktoren gibt, die diese Transfers beeinflussen (Status der betreffenden Sprachen und bestimmte Eigenschaften der Sprecher).
\end{abstract}

Schlüsselwörter: semantische Kategorisierung, Sprachtransfer, konzeptueller Transfer, Katalanisch, Amazigh, Zweisprachigkeit, Mehrsprachigkei 